\title{
Article
}

\section{High-Performance Hole-Transport Polyurethanes for Light-Emitting Diodes Applications}

Chao-Hui Kuo, Kang-Chun Peng, Li-Chung Kuo, Kuei-Hui

Yang, Jiun-Haw Lee, Man-kit Leung, and Kuo-Huang Hsieh

Chem. Mater., 2006, 18 (17), 4121-4129 • DOI: 10.1021/cm060124w

Downloaded from http://pubs.acs.org on November 17, 2008

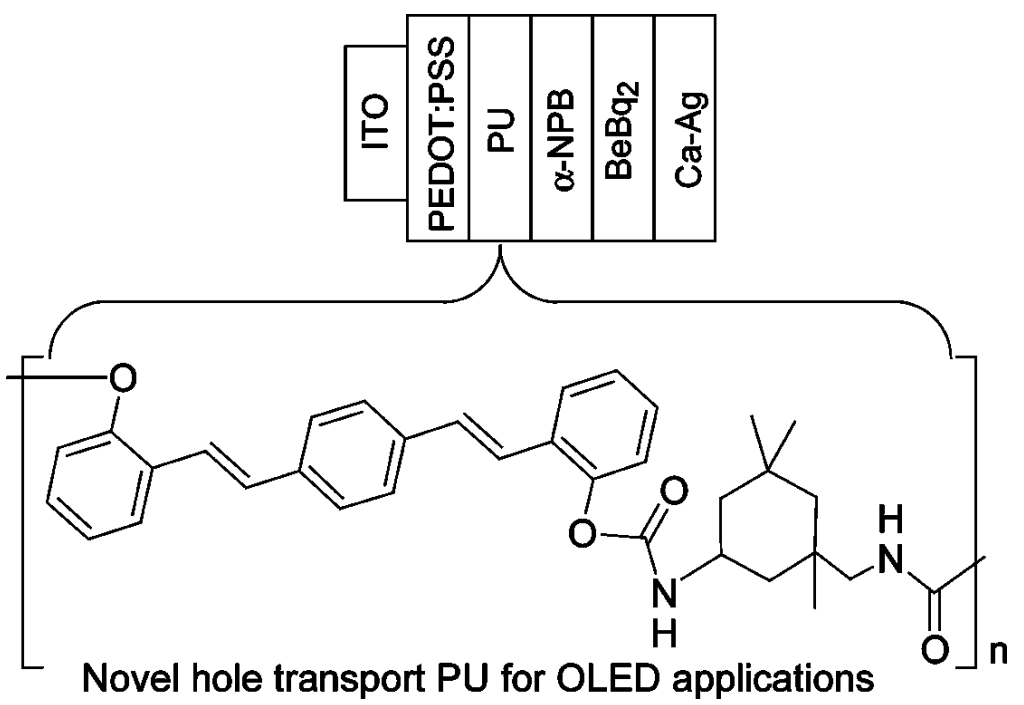

\section{More About This Article}

Additional resources and features associated with this article are available within the HTML version:

- Supporting Information

- $\quad$ Links to the 5 articles that cite this article, as of the time of this article download

- Access to high resolution figures

- $\quad$ Links to articles and content related to this article

- $\quad$ Copyright permission to reproduce figures and/or text from this article

\section{View the Full Text HTML}




\title{
High-Performance Hole-Transport Polyurethanes for Light-Emitting Diodes Applications
}

\author{
Chao-Hui Kuo, ${ }^{\dagger}$ Kang-Chun Peng," Li-Chung Kuo, ${ }^{\S}$ Kuei-Hui Yang, ${ }^{\S}$ Jiun-Haw Lee,, ,l

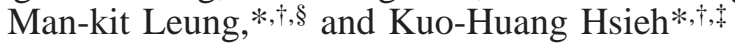 \\ Institute of Polymer Science and Engineering, Department of Chemical Engineering, Department of \\ Chemistry, and Graduate Institute of Electro-optical Engineering and Department of Electrical \\ Engineering, National Taiwan University, Taipei, Taiwan \\ Received January 18, 2006. Revised Manuscript Received June 3, 2006
}

\begin{abstract}
A novel family of hole-transport polyurethanes (PUs) has been developed. The PUs were prepared from the condensation polymerization of isophorone diisocyanate (IPDI) with (E,E)-1,4-bis(2-hydroxystyryl)benzene, an oligo $p$-phenylene- $(E)$-vinylene (OPV) unit, and various amounts of 2,5-bis(4hydroxyphenyl)-1,3,4-oxadiazole (OXD), as well as with 4-tert-butyl phenol as the terminal group. The PUs demonstrates superior properties that were concluded on the basis of the improved current injection in the corresponding hole-only device. The OLED device with the OPV-PU interfacial layer inserted in ITO/PEDOT:PSS(20 nm)/PU(30 nm)/ $\alpha-N P B(10 \mathrm{~nm}) / \mathrm{Bebq}_{2}(20 \mathrm{~nm}) / \mathrm{Ca}(10 \mathrm{~nm}) / \mathrm{Ag}(100 \mathrm{~nm})$ has a dramatic voltage reduction of $2.5 \mathrm{~V}$ under the current density of $100 \mathrm{~mA} / \mathrm{cm}^{2}$. When compared to the control device, the current efficiency was improved 2.37 times. The maximum brightness increased to 14900 $\mathrm{cd} / \mathrm{m}^{2}$ in comparison to that of $5780 \mathrm{~cd} / \mathrm{m}^{2}$ for the control device. The performance of the OLED devices was fine-tuned by adjusting the combination of the OPV and OXD units to reach electron-hole balanced conditions. The maximum current efficiency increased to $4.12 \mathrm{~cd} / \mathrm{A}$ at $5.5 \mathrm{~V}$ when the PU layer of OPV: OXD $=67: 33$ was used.
\end{abstract}

\section{Introduction}

Significant scientific and technological progress has recently been achieved in the area of thin film organic electronic devices. ${ }^{1}$ To achieve optimal device performance, it is sometimes desirable to have multilayer structures that have discrete semiconducting properties. ${ }^{2}$ Depending on the function of the devices, some layers would have optoelectronic function such as light-emissive properties, ${ }^{3}$ or light-

* To whom correspondence should be addressed. E-mail: jhlee@cc.ee.ntu.edu.tw (J.-H. Lee); mkleung@ntu.edu.tw (M.-k. Leung); khhsieh@ntu.edu.tw (K.-H. Hsieh).

$\dagger$ Institute of Polymer Science and Engineering.

$¥$ Department of Chemical Engineering.

$\S$ Department of Chemistry.

"Graduate Institute of Electro-optical Engineering and Department of Electrical Engineering.

(1) (a) Tang, C. W.; Vanslyke, S. A. Appl. Phys. Lett. 1987, 51, 913. (b) Burroughes, J. H.; Bradley, D. D. C.; Brown, A. R.; Marks, R. N.; Mackay, K.; Friend, R. H.; Burn, P. L.; Holmes, A. B. Nature 1990, 347, 539. (c) Forrest, S. R. Chem. Rev. 1997, 97, 1793-1896.

(2) For reviews, see (a) Kelley, T. W.; Baude, P. F.; Gerlach, C.; Ender, D. E.; Muyres, D.; Haase, M. A.; Vogel, D. E.; Theiss, S. D. Chem. Mater. 2004, 16, 4413-4422. For electron-transport materials, see: (b) Kulkarni, A. P.; Tonzola, C. J.; Babel, A.; Jenekhe, S. J. Chem. Mater. 2004, 16, 4556-4573. (c) Li, X.-C.; Hughes, G.; Bryce, M. R. J. Mater. Chem. 2005, 15, 94-107. (d) Grimsdale, A. C.; Cervini, R.; Holmes, A. B.; Moratti, S. C.; Yong, T. M.; Gruner, J.; Friend, R. H. Synthesis and properties of novel high-electron-affinity polymers for electroluminescent devices; ACS Symposium Series, 672 (Photonic and Optoelectronic Polymers); American Chemical Society: Washington, DC, 1997; pp 322-344. For hole-transport materials, see: (e) Shirota, Y. J. Mater. Chem. 2000, 10, 1.

(3) (a) Song; Y. H.; Yeh, S. J.; Chen, C. T.; Chi, Y.; Liu C. S.; Yu, J. K.; Hu, Y. H.; Chou, P. T.; Peng, S. M.; Lee, G. H. Adv. Funct. Mater. 2004, 16, 1585. (b) D'Andrade, B. W.; Forrest, S. R. Adv. Mater. 2004, 16, 1585. (c) Liao, L. S.; Klubek, K. P.; Tang, C. W. Appl. Phys. Lett. 2004, 84, 167. harvesting and charge generation capabilities. ${ }^{4,5}$ Although in principle small organic molecules or polymeric materials can both be adopted for applications, small molecules have greater advantages with their higher purity and volatility. On one hand, a variety of organic multilayer electronic devices could be effectively fabricated through sequential vacuum deposition. On the other hand, polymeric materials are of great interest due to their potential applications on flexible devices with large surfaces. ${ }^{6}$ However, fabrication of polymeric multilayer structures is somewhat difficult. During the last few decades, much research progress on different dimensions has been continuously reported about constructing polymeric multilayer devices. ${ }^{7}$

Polymeric light-emitting diodes (PLEDs) have attracted much attention during the past decade due to their potential

(4) (a) Gust, D.; Moore, T. A.; Moore, A. L. Acc. Chem. Res. 2001, 34, 40-48. (b) Chrisstoffels, L. A. J.; Adronov, A.; Fréchet J. M. J Angew. Chem., Int. Ed. 2000, 39, 2163-2167.

(5) (a) Ostroverkhova, O.; Moerner, W. E. Chem. Rev. 2004, 104, 32673314. (b) Hagfeldt, A.; Gratzel, M. Acc. Chem. Res. 2000, 33, 269277.

(6) (a) Gu G.; Shen Z.; Burrows, P. E.; Forrest S. R. Adv. Mater. 1997, 9. 725-728. (b) Tsutsui, T.; Fujita, K. Adv. Mater. 2002, 14, 949952. (c) Yang, Y.; Huang, Q.; Metz, A. W.; Ni, J.; Jin, S.; Marks, T. J.; Madsen, M. E.; DiVenere, A.; Ho, S.-T. Adv. Mater. 2004, 16, 321-324. (d) Lee, K. J.; Motala, M. J.; Meitl, M. A.; Childs, W. R.; Menard, E.; Shim, A. K.; Rogers, J. A.; Nuzzo, R. G. Adv. Mater. 2005, 17, 2332-2336. (e) Hide, F.; Díaz-García, M. A.; Schwartz, B. J.; Heeger, A. J. Acc. Chem. Res. 1997, 30, 430. (f) Greenham, N. C.; Friend, R. H. In Solid State Physics; Enhrenreich, H., Spaepen, F., Eds.; Academic: San Diego, 1995; Vol. 49, pp 1-149. (g) Gustafsson, G.; Cao, Y.; Treacy, G. M.; Klavetter, F.; Colaneri, N.; Heeger, A. J. Nature 1992, 357, 477.

(7) Sprengard, R.; Bonrad, K.; Däubler, T. K.; Frank, T.; Hagemann, V.; Köhler, I.; Pommerehne, J.; Ottermann, C.; Voges, F.; Vingerling, B. Proc. SPIE-Int. Soc. Opt. Eng. 2004, 5519, 173-183. 
application in flexible flat panel displays as well as luminescent devices. The efficiency of OLED or PLED devices is dependent on many factors, including balanced injection of charge carriers, quantum efficiency of the light-emitting layer, and the charge confinement for bipolar recombination..$^{8-10}$ To achieve high-performance devices, multilayer OLED structures have been intensively developed. However, applying the concept of multilayer structures to PLED devices is somewhat problematic since typical solvents such as chloroform, dichloroethane, toluene, or xylene would dissolve most electroluminescent (EL) polymers. Therefore, fabrication of multilayer EL devices through layer-by-layer spin coating or inkjet printing would be difficult.

To establish multilayer polymer devices, many different approaches have been reported to bypass the solubility problem. For example, insoluble polymeric film could be directly formed on a substrate by thermal treatments ${ }^{1 b, 11}$ or chemical cross-linking before applying the second layer. ${ }^{12}$ On the other hand, self-assembly methods ${ }^{13}$ or electropolymerization provides other options to avoid the solubility problem. ${ }^{14}$

One of the most direct approaches is to have a series of functional polymers that could alternatively be spin-coated on the substrate. It requires polymers that are dissolved respectively in polar and nonpolar orthogonal solvent systems. ${ }^{15}$ Since many famous light-emitting polymers in the literature such as poly(p-phenylene-(E)-vinylenes) ${ }^{16}$ or poly-

(8) Qiu, Y.; Gao, Y.; Wei, P.; Wang, L. Appl. Phys. Lett. 2002, 80, 2628.

(9) Baldo, M. A.; Lamansky, S.; Burrows, P. E.; Thompson, M. E.; Forrest, S. R. Appl. Phys. Lett. 1999, 75, 4.

(10) Xie, Z. Y.; Hung, L. S.; Lee, S. T. Appl. Phys. Lett. 2001, 79, 1048.

(11) (a) Ho, G.-K.; Meng, H.-F.; Lin, S.-C.; Horng, S.-F.; Hsu, C.-S.; Chen, L.-C.; Chang, S.-M. Appl. Phys. Lett. 2004, 85, 4576-4578.

(12) Nuyken, O.; Bacher, E.; Braig, T.; Fáber, R.; Mielke, F.; Rojahn, M.; Wiederhirn, V.; Meerholz, K.; Müller, D. Des. Monomers Polym. 2002, $5,195-210$

(13) (a) Veinot J. G. C.; Marks, T. J. Acc. Chem. Res. 2005, 38, 632. (b) Ho, P. K. H.; Kim, J.-S.; Burroughes, J. H.; Becker, H.; Li, S. F. Y.; Brown, T. M.; Cacialli, F.; Friend, R. H. Nature 2000, 404, 481484. (c) Flink, S.; van Veggel, F. C. J. M.; Reinhoudt, D. N. Adv. Mater. 2000, 12, 1315. (d) Bliznyuk, V.; Ruhstaller, B.; Brock, P. J.; Scherf, U.; Carter, S. A. Adv. Mater. 1999, 11, 1257. (e) Ho, P. K. H.; Granström, M.; Friend, R. H.; Greenham, N. C. Adv. Mater. 1998, 10, 769. (f) Horowitz, G. Belannoy, P.; Bouchriha, H.; Deloffre, F.; Fave, J.-L.; Garnier, F.; Hajlaoui, R.; Heyman, M.; Kouki, F.; Valat, P.; Wintgens, V.; Yassar, A. Adv. Mater. 1994, 6, 752. (g) Geiger, F.; Stoldt, M.; Schweizer, H.; Bäuerle, P.; Umbach, E. Adv. Mater. 1993, 5, 922. (h) Lee, J.; Jung, B.-J.; Lee, J.-I.; Chu, H. Y.; Do, L.M.; Shim, H. K. J. Mater. Chem. 2002, 12, 3494-3498.

(14) (a) Chou, M.-Y.; Leung, M.-k.; Su, Y. O.; Chiang, C. L.; Lin, C.-C.; Liu, J.-H.; Kuo, C.-K.; Mou, C.-Y. Chem. Mater. 2004, 16, 654661. (b) Leung, M.-k.; Chou, M.-Y.; Su, Y. O.; Chiang, C.-L.; Chen, H.-L.; Yang, C. F., Yang, C.-C.; Lin, C.-C.; Chen, H.-T. Org. Lett. 2003, 5, 839. (c) Onishi, K.; Advincula, R. C. Polym. Prepr. (Am. Chem. Soc., Div. Polym. Chem.) 2003, 44, 1167. (d) Zhang, F.; Petr, A.; Kirbach, U.; Dunsch, L. J. Mater. Chem. 2003, 13, 265. (e) Onishi, K.; Advincula, R. C. Polym. Mater. Sci. Eng. 2002, 86, 259. (f) Wang, G.; Hu, X.; Wong, T. K. S. Appl. Surf. Sci. 2001, 174 (3-4), 185190. (g) Xia, C.; Advincula, R. C. Chem. Mater. 2001, 13, 1682. (h) Wang, G.; Hu, X.; Wong, T. K. S. J. Solid State Electrochem. 2001, 5, 150-153. (i) Roncali, J. J. Mater. Chem. 1999, 9, 1875. (j) Komaba, S.; Amano, A.; Osaka, T. J. Electroanal. Chem. 1997, 430, 97. (k) Favre, C.; Abello, L.; Delabouglise, D. Adv. Mater. 1997, 9, 722. (l) Martin, C. R. Acc. Chem. Res. 1995, 28, 61. (m) Osaka, T.; Komaba, S.; Fujihana, K.; Okamoto, N.; Kaneko, N. Chem. Lett. 1995, 11, $1023-4$.

(15) (a) Ma, W.; Iyer, P. K.; Gong, X.; Liu, B.; Moses, D.; Bazan, G. C.; Heeger, A. J. Adv. Mater. 2005, 17, 274-277. (b) Gong, X.; Wang, S.; Moses, D.; Bazan, G. C.; Heeger, A. J. Adv. Mater. 2005, 17, 2053-2058. (c) Book, K.; Baessler, H.; Elschner, A.; Kirchmeyer, S. Org. Electron. 2003, 4, 227-232. fluorenes ${ }^{17}$ are soluble in nonpolar solvents, electron- and hole-transporting polymers that are soluble in polar solvents are highly desired. A well-known example is the dual-layer structure derived from the water-soluble PEDOT:PSS and nonpolar light-emitting polymers.

Polyurethanes (PUs) are common polymers that have been widely used for industrial applications. ${ }^{18}$ Due to their good solubility in polar aprotic solvent such as DMF or NMP, they are appropriate candidates for study. Indeed, several studies about the applications of PUs on PLEDs have recently been reported. ${ }^{19}$ Furthermore, PUs are an attractive area of study for chemists because of their metal-ion free synthetic pathways. $^{20}$ A low level of metal-ion contaminants is a crucial requirement for high-performance electronic polymers. Proper synthetic approaches that could avoid contamination from metal ions are highly desired. Since PUs are usually prepared from a clean procedure of the condensation of diisocyanate and diol monomers, in which no metal-ioncontaining reagents are involved, ionic contaminants in the polymers should be minimal. ${ }^{21}$

In addition, interfacial conditions between electrodes and conducting layers are known to play important roles in the efficiency of organic electroluminescent diodes. ${ }^{22}$ It has been reported that grafting of dipolar molecules on the ITO surface would enhance the performance of the devices. ${ }^{19 \mathrm{~d}}$ Therefore, polar polymers such as PUs are particularly attractive targets to investigate. In the present article, we report the preparation and study of the high-performance hole-transporting polyurethanes (PUs) 1-7 and their applications to light-emitting diodes (LED).

\section{Results and Discussion}

Design of the Polymers. The PUs studied in the present research contain the following: (1) segments having holetransport or electron-transport electronic functions; (2) dipolar carbamate components; and (3) alkyl spacers connecting the carbamate groups. Since it has been reported that oligo- $p$ phenylene- $(E)$-vinylenes and aromatic oxadiazoles (OXD)

(16) (a) Burn, P. L.; Grice, A. W.; Tajbakhsh, A.; Bradley, D. D. C.; Thomas, A. C. Adv. Mater. 1997, 9, 1171-1174. (b) Kraft, A.; Grimsdale, A. C.; Holmes, A. B. Angew. Chem., Int. Ed. 1998, 37, 402-428. (c) Becker, H.; Spreitzer, H.; Kreuder, W.; Kluge, E.; Schenk, H.; Parker, I.; Cao, Y. Adv. Mater. 2000, 12, 130-133.

(17) Bernius, M. T.; Inbasekaran, M.; O'Brien, J.; Wu, W. Adv. Mater. 2000, 12, 1737-1750.

(18) Randall, D., Lee, S., Eds. The polyurethanes book; Wiley: New York, 2002.

(19) (a) Park, J. H.; Park, O. O.; Yu, J. W.; Kim, J. K.; Kim, Y. C. Appl. Phys. Lett. 2004, 84, 1783. (b) Wang, H.-L.; Wen, T.-C. Mater. Chem Phys. 2003, 82, 341-346. (c) Ishchenko, A. Polym. Adv. Technol 2002, 13, 744-752. (d) Lim, H.; Noh, J. Y.; Lee, G. H.; Lee, S. E.; Jeong, H.; Lee, K.; Cha, M.; Suh, H.; Ha, C.-S. Thin Solid Films 2000, 363, 152-155. (e) Jeong, H.; Zou, D.; Tsutsui, T.; Ha, C.-S. Thin Solid Films 2000, 363, 279-281. (f) Lee, T. W.; Park, O. O. Appl. Phys. Lett. 2000, 76, 3161-3163. (g) Jeong, H.; Ha, C.-S. Mol. Cryst. Liq. Cryst. Sci. Technol., Sect. A 1999, 337, 349-352.

(20) Sandler, S. R.; Karo, W. Polymer Syntheses; Academic Press: New York, 1992; Chapter 8.

(21) Caraculacu, A. A.; Coseri, S. Prog. Polym. Sci. 2001, 26, 799-851.

(22) (a) Ishii, H.; Hayashi, N.; Ito, E.; Washizu, Y.; Sugi, K.; Kimura, Y.; Niwano, M.; Ouchi, Y.; Seki, K. Phys. Status Solidi A 2004, 201, 1075-1094. (b) Ishii, H.; Sugiyama, K.; Ito, E.; Seki, K. Adv. Mater. 1999, 11, 605-625. (c) Ishii, H.; Seki, K. Conjugated Polymer and Molecular Interfaces; Salaneck, W. R., Seki, K., Kahn, A., Pireaux, J.-J., Eds.; Marcel Dekker: New York, 2002; pp 293-349. 
Scheme 1

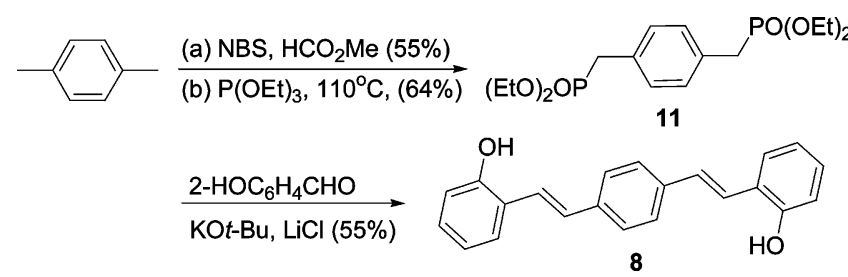

Scheme 2

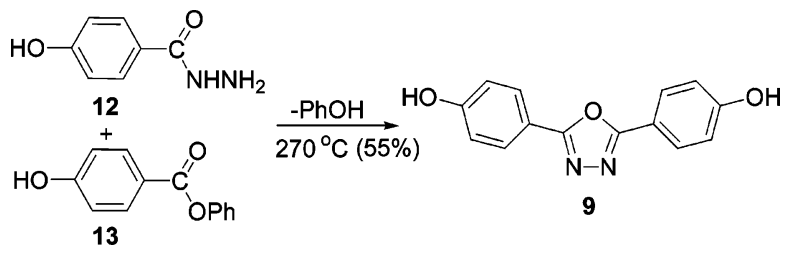

are good complementary pair of hole-transport and electrontransport materials, ${ }^{23}$ we selected monomers 8 and 9 as basic components to construct the PUs. To systematically evaluate the performance of the polymers, homo OPV-PU 1, OXDOPV-PU copolymers 2-6, homo OXD-PU 7, and nonPU-based polymer $\mathbf{1 0}$ were prepared for comparison.

Monomer Synthesis. Monomers 8 and 9, denoted as OPV $\mathbf{8}$ and OXD 9, were prepared respectively as illustrated in Schemes 1 and 2. OPV 8 was prepared in three steps from $p$-xylene. Radical bromination of $p$-xylene led to $\alpha, \alpha^{\prime}$ dibromo- $p$-xylene ${ }^{24}$ in reasonable yields. Many reaction conditions have been attempted and methylformate was found the most effective solvent to provide the desired dibromide in $55 \%$ yield. Treatment of $\alpha, \alpha^{\prime}$-dibromo- $p$-xylene with triethyl phosphite afforded bis(diethylphosphonate) 11 $(64 \%)^{25}$ that was further condensed with 2-hydroxybenzaldehyde under the Wadsworth-Emmons-Wittig conditions to give the target OPV monomer $8(55 \%){ }^{26}$ It is noteworthy to mention that an oxygen-free atmosphere is critical for obtaining a high-quality product in this step. Generated brown-colored side products would otherwise make the purification difficult.

OXD 9 was prepared from direct condensation of 4-hydroxybenzoic acid hydrazide (12) with 4-hydroxybenzoic acid phenyl ester (13) according to a literature procedure. ${ }^{27}$ Phenol was removed as a byproduct through distillation during reaction. The product was then recrystallized from a solution of $N, N$-dimethylacetamide and water to give 9 in a $55 \%$ yield.

Polymer Synthesis and Characterization. The incorporation of conjugated functional OPV 8 and OXD 9 (Scheme

(23) (a) Wang, Z.; Yang, X.; Chen, X.; Xu, Z.; Xu, X. Thin Solid Films 2000, 363, 94-97. (b) Chen, Z.-K.; Meng, H.; Lai, Y.-H.; Huang, W. Macromolecules 1999, 32, 4351. (c) Ahn, T.; Jang, M. S.; Shim, H.K.; Hwang, D.-H.; Zyung, T. Macromolecules 1999, 32, 3279-3285. (d) Peng, Z.; Bao, Z.; Galvin, M. E. Chem. Mater. 1998, 10, 20862090. (e) Li, X. C.; Cacialli, F.; Giles, M.; Grüber, J.; Friend, R. H.; Holmes, A. B.; Moratti, S. C.; Yong, T. M. Adv. Mater. 1995, 898900. (f) Hay, M.; Kalvetter, F. L. J. Am. Chem. Soc. 1995, 117, 7112 7118.

(24) Sket, B.; Zupan, M. J. Org. Chem. 1986, 51, 929-931.

(25) Kauffman, J. M.; Moyna, G. J. Org. Chem. 2003, 68, 839-853.

(26) Tewari, R. S.; Kumari, N.; Kendurkar, P. S. Indian J. Chem. (B) 1977, $15,753-755$.

(27) Connell, J. W.; Hergenrother, P. M.; Wolf, P. Polymer 1992, 33, 350711
Scheme 3

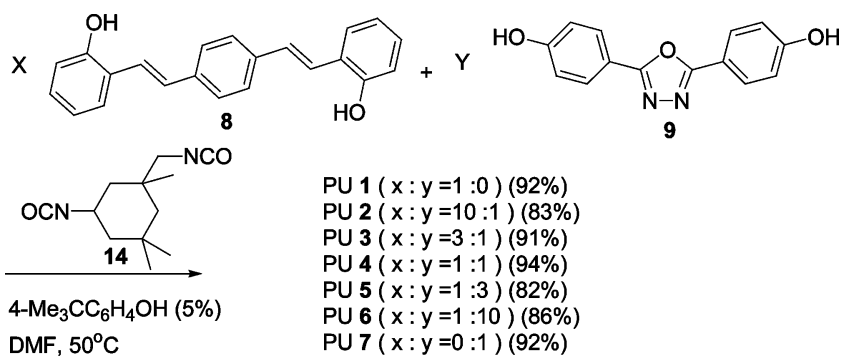

Table 1. Characterization and Optical Properties of PUs 1-7 and Polymer 10

\begin{tabular}{|c|c|c|c|c|c|c|c|c|}
\hline & $\begin{array}{c}\text { calibrated } \\
x: y \text { ratio }\end{array}$ & $\mathrm{Mw}$ & $\mathrm{DP}^{a}$ & $\begin{array}{c}T_{\mathrm{g}} \\
\left({ }^{\circ} \mathrm{C}\right)\end{array}$ & $\begin{array}{c}T_{\mathrm{d}} \\
\left({ }^{\circ} \mathrm{C}\right)\end{array}$ & $\begin{array}{l}\mathrm{UV}(\mathrm{nm})^{b} \\
\text { max/edge }\end{array}$ & $\begin{array}{l}\mathrm{UV}(\mathrm{nm}) \\
\text { (film) }\end{array}$ & $\begin{array}{c}\mathrm{HOMO}^{c} / \mathrm{LUM} \\
(\mathrm{eV})\end{array}$ \\
\hline & & 9 & 2 & 84 & 276 & 372407 & 372 & $-562 /-270$ \\
\hline & $91 /$ & 9. & 2.50 & 88 & 256 & & & \\
\hline & $67 /$ & 9.0 & 2.43 & 92 & 262 & & & \\
\hline & $61 / 3$ & 7.5 & 2.45 & 103 & 263 & & 39 & \\
\hline & & & & 106 & 301 & & & \\
\hline & 16 & & & 115 & 298 & & & \\
\hline & & 9. & 2.20 & 130 & 325 & $<30$ & $<300$ & 2.22 \\
\hline U & & 18.6 & 2.04 & 91 & 401 & $364 / 412$ & 378 & $-5.31 /-2.29$ \\
\hline
\end{tabular}

${ }^{a}$ From GPC. ${ }^{b}$ Solution. ${ }^{c}$ From AC-2 measurement. ${ }^{d}$ Based on the optical band gap of film.

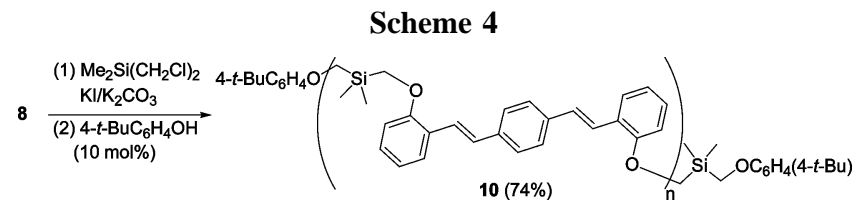

3) into the polar polyurethanes was achieved by condensation of the corresponding phenolic monomers with commercially available isophorone diisocyanate (IPDI) $\mathbf{1 4}$ in dried DMF to give polymers 1 and $\mathbf{7}$, respectively. The OPV-OXD copolymers 2-6 were prepared in a similar fashion. The OPV-OXD feeding ratios of 10:1, 3:1, 1:1, 1:3, and 1:10 were adopted in the present study. The molecular weight of the prepared polymers and their thermal behavior, including $T_{\mathrm{g}}$ and $T_{\mathrm{d}}$, are summarized in Table 1 . The molecular weight of the polymers was determined by gel-permeation chromatography (GPC) analysis against polystyrene standard in DMF. In addition, the GPC results are in good agreement with the estimated molecular weights based on the NMR integrations.

To evaluate the effects of the carbamate groups on the EL performance, a silane-based polymer $\mathbf{1 0}$ was therefore prepared by reaction of $\mathbf{8}$ with $\mathrm{Me}_{2} \mathrm{Si}\left(\mathrm{CH}_{2} \mathrm{Cl}\right)_{2}$ in the presence of $\mathrm{KI} / \mathrm{K}_{2} \mathrm{CO}_{3}$ (Scheme 4) for comparison. ${ }^{28}$

The characterization and optical properties of the studied polymers in diluted solutions and in solid films were summarized in Table 1. The homo-polymer $\mathbf{1}$ and copolymers 2-6 exhibit an absorption maximum in the region of $355-375 \mathrm{~nm}$ that are assigned to the $\pi-\pi^{*}$ electronic transitions of the OPV units. No significant spectral shift of their solution spectra was observed, indicating that the intrachain OPV/OXD interactions were minimal.

This $\pi-\pi^{*}$ electronic transition band provided us a good entry to calibrate the actual OPV/OXD ratio in our PUs.

(28) Vivet, B.; Cavelier, F.; Martinez, J. Eur. J. Org. Chem. 2000, 807811. 


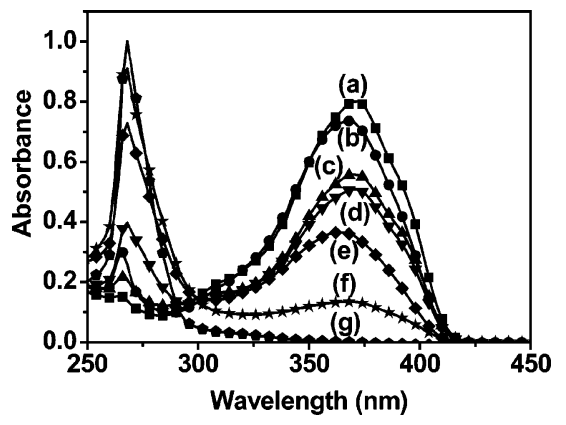

Figure 1. UV-Vis absorption spectra of polymer solutions $(0.1 \mathrm{mg} / \mathrm{mL})$ in DMF of 1-7: (a) 1; (b) 2; (c) 3; (d) 4; (e) 5; (f) 6; (g) 7 .

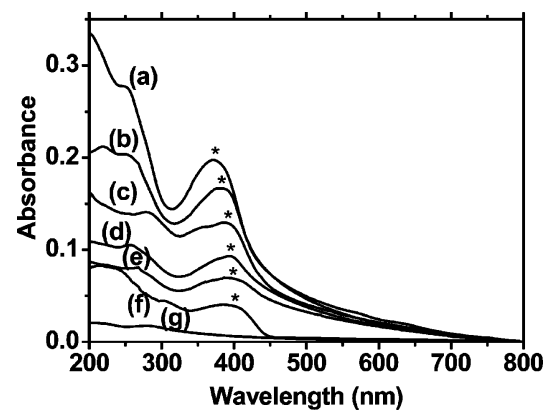

Figure 2. UV-Vis absorption spectra of polymer films of 1-7: (a) 1; (b) 2; (c) 3; (d) 4; (e) 5; (f) 6; (g) 7 .

Since the reactivity of monomers $\mathbf{8}$ and $\mathbf{9}$ toward the IPDI 14 are different in principle, the actual OPV/OXD ratio in the PUs may be different from the feeding ratio.

Figure 1 exhibits the UV-Vis absorption spectra for polymer solutions of $\mathbf{1 - 7}$ in DMF with identical concentrations of $0.1 \mathrm{mg} / \mathrm{mL}$. The OPV absorption peaked at $360 \mathrm{~nm}$ does not overlap with that of the OXD group and the absorbance reduces along with the decrease of the OPV content. We therefore selected the absorption intensity peak at $360 \mathrm{~nm}$ as reference to calibrate the percentage of OPV in the polymer. The calibrated OPV/OXD ratios are listed in Table 1. The mathematical deductions for the calibration method are summarized in the Experimental Section.

Interchain OPV/OXD interactions are noticeable in the solid phase, however. The solid films of 1-6 exhibit systematic spectral shifts of their absorption spectra: from $\lambda_{\max }$ of $372 \mathrm{~nm}$ for polymer $\mathbf{1}$ gradually shifted to $\lambda_{\max }$ of $402 \mathrm{~nm}$ for polymer 6 (Figure 2). Since the probability of having $\pi$ coordination for an OPV moiety with OXD units in the solid matrix increases when the OXD/OPV ratio increases, one may perceive that the bathochromic-shift phenomenon is coming from the OXD/OPV $\pi-\pi$ interactions. The bathochromic-shift phenomenon also implied that the electronic properties of the OPV moieties were perhaps moderated by the adjacent OXD components.

Further evidence about the OPV-OXD interactions was obtained by photoelectron spectrometric measurements ${ }^{29}$ (Riken Keiki AC-2) in which the HOMO energy level of the polymeric films was directly measured. The LUMO energy levels were then calculated on the basis of their HOMO energy levels and the optical band gap of the polymers.

(29) (a) Trigwell, S.; Grable, N.; Yurteri, C. U.; Mazumder, M. K. Seo, S. Surf. Interface Anal. 1998, 26, 483-489. (b) Nakajima, Y.; Yamashita, D. Japan Patent JP2005257538, CAN 143:338608, AN 2005:1023803.

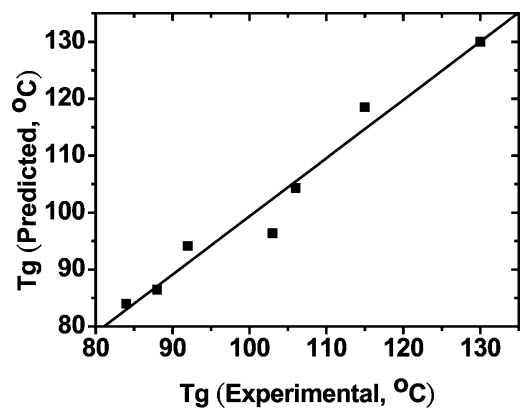

Figure 3. Correlation plot of the calculated $T_{\mathrm{g}}$ versus the measured $T_{\mathrm{g}}$ of 1-7.

The value of the HOMO levels gradually shifts from 5.6 to $5.8 \mathrm{eV}$, indicating that the HOMOs of the OPV units were stabilized in the presence of the adjacent OXD units in the solid matrix. On the other hand, the spectral red shift suggested that the HOMO-LUMO gap becomes smaller when the OXD/OPV ratio increases. These results indicated that the OPV LUMO stabilization effects in the solid matrix are even more significant than that of the HOMO.

Thermal Properties. The thermal behaviors of the polymers have been studied by differential scanning calorimetry (DSC) as well as by thermogravimetric analysis (TGA). Polymer 1 exhibits a relatively low glass transition temperature $\left(T_{\mathrm{g}}\right)$ of $84^{\circ} \mathrm{C}$ in comparison to 7 , which shows a higher $T_{\mathrm{g}}$ of $130{ }^{\circ} \mathrm{C}$. The lower $T_{\mathrm{g}}$ of $\mathbf{1}$ is probably due to the rotational modes of the OPV units. Copolymers 2-6 exhibit a single $T_{\mathrm{g}}$ with the value gradually shifted from 93 to $115{ }^{\circ} \mathrm{C}$. The $T_{\mathrm{g}}$ values fit well with the linear WLF equation of $1 / T_{\mathrm{g}}=W^{\mathrm{OPV}}\left(1 / T_{\mathrm{g}}^{\mathrm{OPV}}\right)+W^{\mathrm{OXD}}\left(1 / T_{\mathrm{g}}^{\mathrm{OXD}}\right)$ with the correlation coefficient of $R=0.98$ (Figure 2), in which $W^{\mathrm{OPV}}$ and $W^{\mathrm{OXD}}$ are the weight fractions of the OPV and the OXD units in the polymer and $T_{\mathrm{g}}^{\mathrm{OPV}}$ and $T_{\mathrm{g}}^{\mathrm{OXD}}$ are the $T_{\mathrm{g}}$ 's of $\mathbf{1}$ and 7, respectively (Figure 3). ${ }^{30}$ This result is consistent with the assumption that the copolymers are random copolymers rather than block copolymers.

Hole-Injection and -Transport Properties of Polymers 1-7 and 10. The hole-injection and -transport properties of 1-7 were evaluated by a hole-only approach. ${ }^{31}$ In the study, poly(3,4-ethylenedioxythiophene) - polystyrene sulfonates (PEDOT:PSS), $N, N^{\prime}$-diphenyl- $N, N^{\prime}$-bis(1-naphthyl)-1,1'-biphenyl-4, $4^{\prime}$-diamine $(\alpha-\mathrm{NPB})$, and silver $(\mathrm{Ag})$ are used as the hole-injection and electron-blocking and the cathode materials, respectively. The device structure, ITO/PEDOT:PSS$(20 \mathrm{~nm}) / \mathrm{PU}(30 \mathrm{~nm}) / \alpha-\mathrm{NPB}(70 \mathrm{~nm}) / \mathrm{Ag}(100 \mathrm{~nm})$, was adopted in which only the hole current is expected. A large barrier for the electron-injection process from $\mathrm{Ag}$ to $\alpha$-NPB is anticipated to inhibit the electron current through the device. The $J-V$ curves for the devices are shown in Figure 4. The hole current was greatly enhanced when the PU layer of $\mathbf{1}$, $\mathbf{2}$, or $\mathbf{3}$ was applied. These results reflected that the OPV dominant PUs were extremely good hole-injection materials. In the presence of the OPV-based layer of $\mathbf{1}, \mathbf{2}$, and $\mathbf{3}$, the current of the device could reach $100 \mathrm{~mA} / \mathrm{cm}^{2}$ at $10.5,11.3$, and $12.1 \mathrm{~V}$, respectively. In contrast, for the control $\alpha-\mathrm{NPB}$

(30) Haseebuddin, S.; Raju, K. V. S. N.; Yaseen, M. Prog. Org. Coatings 1997, 30, 25-30.

(31) Kim, Y.; Bae, K. H.; Jeong, Y. Y.; Choi, D. K.; Ha, C.-S. Chem. Mater. 2004, 16, 5051-5057. 


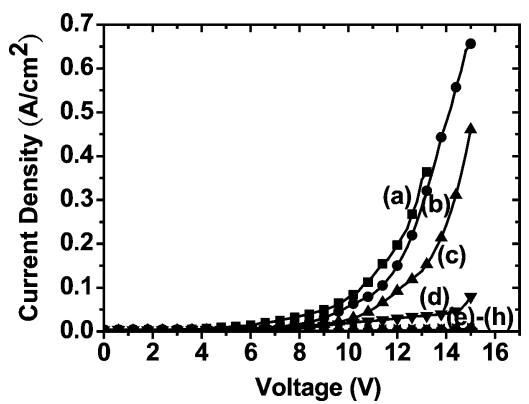

Figure 4. Hole-only experiments for (a) 1 ; (b) 2 ; (c) 3; (d) 4; (e) 5; (f) 6 ; (g) 7; (h) $\alpha$-NPB only.

Table 2. EL Performance of PUs 1-7 and Polymer 10 in Devices of ITO/PEDOT:PSS $(20 \mathrm{~nm}) / \operatorname{Polymer}(30 \mathrm{~nm}) / \alpha-\mathrm{NPB}(10 \mathrm{~nm}) / \mathrm{Bebq}_{2}(20$ $\mathrm{nm}) / \mathbf{C a}(10 \mathrm{~nm}) / \mathbf{A g}(100 \mathrm{~nm})$

\begin{tabular}{cccccc}
\hline device & PEDOT:PSS & $\begin{array}{c}\text { polymer } \\
\text { layer }\end{array}$ & $\begin{array}{c}\text { turn-on } \\
\text { voltage }(\mathrm{V}) \\
\text { at } 100 \mathrm{~cd} / \mathrm{m}^{2}\end{array}$ & $\begin{array}{c}\text { brightness } \\
\text { achieved } \\
\left(\mathrm{cd} / \mathrm{m}^{2}\right)\end{array}$ & $\begin{array}{c}\text { efficiency } \\
(\mathrm{cd} / \mathrm{A})\end{array}$ \\
\hline $\mathbf{A}$ & yes & none & 5.3 & 5780 & 1.62 \\
$\mathbf{B}$ & yes & $\mathbf{1}$ & 3.5 & 14900 & 3.84 \\
$\mathbf{C}$ & yes & $\mathbf{2}$ & 3.9 & 13400 & 3.89 \\
$\mathbf{D}$ & yes & $\mathbf{3}$ & 3.8 & 13600 & 4.12 \\
$\mathbf{E}$ & yes & $\mathbf{4}$ & 5.1 & 4850 & 1.63 \\
$\mathbf{F}$ & yes & $\mathbf{6}$ & 6.3 & 1100 & 1.24 \\
$\mathbf{G}$ & yes & $\mathbf{7}$ & 7.3 & 596 & 1.09 \\
$\mathbf{H}$ & yes & $\mathbf{1 0}$ & 6.3 & 2016 & 1.16 \\
$\mathbf{I}$ & no & $\mathbf{1}$ & 7.4 & 2230 & 1.85 \\
$\mathbf{J}$ & no & $\mathbf{2}$ & 7.1 & 1960 & 1.74
\end{tabular}

$(100 \mathrm{~nm})$ hole-only device, the current could only reach 1.6 $\mathrm{mA} / \mathrm{cm}^{2}$ at $13 \mathrm{~V}$.

Effects of the PU Layer on the EL Performance. To evaluate the hole-injection performance of the PUs on a EL device, we adapted bis(10-hydroxybenzo[ $h]$ qinolinato)beryllium $\left(\mathrm{Bebq}_{2}\right)$ as the emitting and electron-transport material of an OLED device with a common structure of ITO/ PEDOT:PSS(20 nm)/PU(30 nm)/ $\alpha-\mathrm{NPB}(10 \mathrm{~nm}) / \mathrm{Bebq}_{2}(20$ $\mathrm{nm}) / \mathrm{Ca}(10 \mathrm{~nm}) / \mathrm{Ag}(100 \mathrm{~nm})$ for comparison. In addition, we selected the standard device of ITO/PEDOT:PSS(20 nm)/ $\alpha-\mathrm{NPB}(10 \mathrm{~nm}) / \mathrm{Bebq}_{2}(20 \mathrm{~nm})_{2} / \mathrm{Ca}(10 \mathrm{~nm}) / \operatorname{Ag}(100 \mathrm{~nm})$, denoted as device $\mathbf{A}$, as our control device for comparison. The performance and mechanisms of the related $\alpha-\mathrm{NPB} /$ bebq $_{2}$-based OLED devices have been previously reported in the literature. ${ }^{32} \mathrm{We}$ assumed that the light-emitting mechanisms in our cases would be similar to that reported in the literature.

In our work, the studied PUs and other reference polymers were applied respectively on top of the PEDOT:PSS layer. The organic hole-transport layer of $\alpha-\mathrm{NPB}$, and the lightemitting and electron-transport layer of $\mathrm{Bebq}_{2}$, and the metallic cathode were then deposited sequentially by physical vapor deposition under the vacuum pressure of $5 \times 10^{-6}$ Torr. The polymers used in the study include homo PUs $\mathbf{1}$ and $\mathbf{7}$, copolymers $\mathbf{2}-\mathbf{4}$ and $\mathbf{6}$, and siloxane polymer $\mathbf{1 0}$. The corresponding devices are denoted respectively as $\mathbf{B}-\mathbf{H}$ and the experimental performances were summarized in Table 2.

Current Characteristic of the OLED. Figure 5 shows the current density-voltage curves $(J-V)$ of devices $\mathbf{A}-\mathbf{H}$.

(32) (a) Lee, J. H.; Wu, C. I.; Liu, S. W.; Huang, C. A.; Chang, Y. Appl. Phys. Lett. 2005, 86, 103506. (b) Hamada, Y.; Sano, T.; Fujita, M.; Fujii, T.; Nishio, Y.; Shibata, K. Chem. Lett. 1993, 5, 905-906.

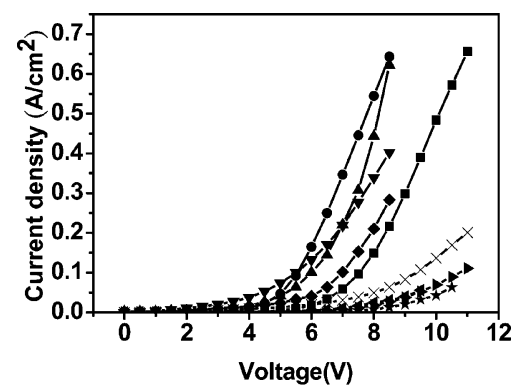

Figure 5. Current density versus voltage characteristic of devices $\mathbf{A}(\mathbf{\square})$, $\mathbf{B}(\bullet), \mathbf{C}(\mathbf{\Delta}), \mathbf{D}(\boldsymbol{\nabla}), \mathbf{E}(\diamond), \mathbf{F}$ (left-facing solid triangle), $\mathbf{G}$ (right-facing solid triangle), and $\mathbf{H}(\times)$.

Dramatic current-density change was observed at the same bias voltage when the PU layer was applied between the layers of PEDOT/PSS and $\alpha$-NPB. At the current density of $100 \mathrm{~mA} / \mathrm{cm}^{2}$, the driving voltage for device $\mathbf{B}$ drops to $5.5 \mathrm{~V}$ in comparison to the driving voltage of $7.5 \mathrm{~V}$ for the control device A. Similar situations were observed for devices $\mathbf{C}$ and $\mathbf{D}$. The change of the driving voltage was governed by at least two possible factors: (a) the holeinjection energy barrier across the PEDOT:PSS/ PU and PU/ $\alpha$-NPB interfaces and (b) the hole mobility in the holetransport matrix. The presence of the PU layer may affect both the factors. When the percentage of the OXD units in the PU increases, the driving voltage for the corresponding devices substantially increases again. The driving voltages of 6, 5.5, and $7 \mathrm{~V}$ were recorded for devices $\mathbf{C}-\mathbf{E}$ at the current density of $100 \mathrm{~mA} / \mathrm{cm}^{2}$, respectively. When PU 6 or homo OXD-polymer $\mathbf{7}$ was applied to devices $\mathbf{F}$ and $\mathbf{G}$, the current injection was significantly inhibited. Since the OXD fragments are known to be hole-block and electron-transport materials, retardation of the hole-injection process by increasing the weight fraction of the OXD segments in the $\mathrm{PU}$ is expected. These results are in good agreement with the trends summarized in the hole-only device study; the OPV fragments are the crucial part for the hole-transport process in the PU matrix. Moreover, since the HOMO level of the polymer $\mathbf{1}$ is about $0.2 \mathrm{~V}$ higher than that of polymer 7, hole injection from ITO into PU 1 should be much easier than that into OXD-based PU 7.

Noteworthy to mention is the role of the carbamate spacer on the device performance. When the highly polar carbamate spacers were replaced by the nonpolar silane-based polymer $\mathbf{1 0}$, the device current of $\mathbf{H}$ significantly dropped and the turn-on voltage increased. This result is contradictory to the prediction based on Fowler-Nordheim (FN) tunneling injection mechanisms. ${ }^{33}$ Although one may expect that better matching of the HOMO levels among ITO $(4.7-4.9 \mathrm{eV})$, $\mathbf{1 0}(5.3 \mathrm{eV})$, and $\alpha$-NPB $(5.4 \mathrm{eV})$ would improve the FowlerNordheim (FN) tunneling injection, we did not observe any significant improvement in this case. On the other hand, a combination of ITO $(4.7-4.9 \mathrm{eV}), \mathbf{1}(5.6 \mathrm{eV})$, and $\alpha-\mathrm{NPB}$ $(5.4 \mathrm{eV})$ gave rise to an OLED with better hole-injection performance. Therefore, we tentatively suggested that the dipole moment alignment of the carbamate linkers along the

(33) Arkhipov, V. I.; Bässler, H.; Wolf, U.; Barth, S. In Conjugated Polymer and Molecular Interfaces; Salaneck, W. R., Seki, K., Kahn, A., Pireaux, J.-J., Eds.; Marcel Dekker: New York, 2002; pp 613-650. 


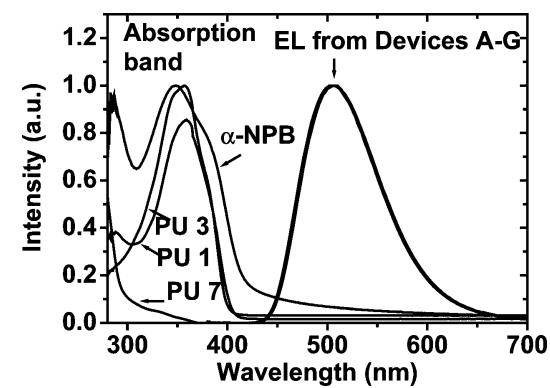

Figure 6. Optical absorption of PUs 1, 3, 7, and $\alpha$-NPB and the EL spectra from devices $\mathbf{A}-\mathbf{G}$.

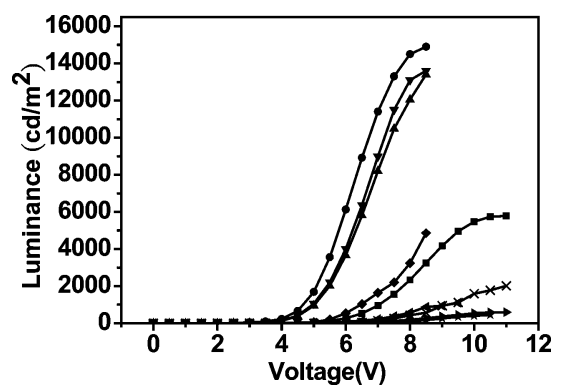

Figure 7. Characteristic brightness-voltage curves for the electroluminescence of devices A $(\mathbf{\square}), \mathbf{B}(\bullet), \mathbf{C}(\mathbf{\Delta}), \mathbf{D}(\mathbf{\nabla}), \mathbf{E}(\bullet), \mathbf{F}$ (left-facing solid triangle), $\mathbf{G}$ (right-facing solid triangle), and $\mathbf{H}(\times)$.

interface between PEDOT:PSS and $\mathbf{1}$ might be an essential factor for the hole-injection process. ${ }^{22}$ On the other hand, a small HOMO-HOMO gap between 1 and $\alpha-\mathrm{NPB}$ benefits for the hole to further diffuse into the $\alpha-\mathrm{NPB}$ and $\mathrm{Bebq}_{2}$ layers.

The use of the PU layer alone on the ITO anode without having the assistance of the PEDOT:PSS hole-injection layer does not show good EL performance (devices $\mathbf{I}$ and $\mathbf{J}$ in Table 2), indicating that the PEDOT:PSS layer still plays an important role in the hole injection in the present devices. The major role of the PU is to modify the interfacial conditions between the PEDOT:PSS and the $\alpha$-NPB layers.

Luminescence and Spectral Properties of the OLED Devices. Figure 6 shows EL spectra of devices $\mathbf{A}-\mathbf{G}$ and the absorption spectra of PUs $\mathbf{1}, \mathbf{3}$, and $\mathbf{7}$ and $\alpha$-NPB. Identical green emission shown in Figure 6 for devices $\mathbf{A}-\mathbf{G}$ suggested that all the LED devices should have identical light-emitting mechanisms and emission zones. The EL peaked at $508 \mathrm{~nm}$ is assigned to the emission from the $\mathrm{Bebq}_{2}$ layer. Previous research revealed that the light emission process occurs most likely at the interfacial region between the layers of $\alpha-\mathrm{NPB}$ and $\mathrm{Bebq}_{2}{ }^{32}$ Introduction of the polymer layer does not alter the emission mechanisms. Since the absorption spectrum of the PU materials has no overlap with the EL spectrum, the presence of the PU layer does not interfere the CIE coordinates of the EL spectrum.

Current Efficiency. Figures 7 and 8 show the luminance versus voltage and the current efficiency versus current density curves of devices $\mathbf{A}-\mathbf{H}$, respectively. The luminescence up to $5780,14900,13403,13600,4852,1100,596$, and $2016 \mathrm{~cd} / \mathrm{m}^{2}$ are recorded for devices $\mathbf{A}-\mathbf{H}$, respectively. The maximum current efficiency of devices $\mathbf{A}-\mathbf{H}$ are 1.62, $3.84,3.89,4.12,1.63,1.24,1.09$, and $1.16 \mathrm{~cd} / \mathrm{A}$ under the operating voltage of $7,5.5,7,7.5,6.5,6.5,7.5$, and $10 \mathrm{~V}$, respectively.

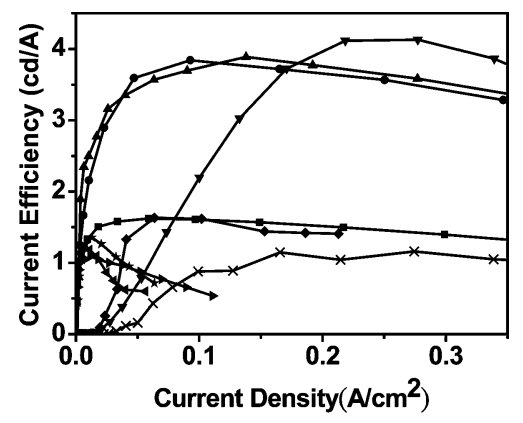

Figure 8. Current efficiency versus current density characteristic of devices $\mathbf{A}(\mathbf{\square}), \mathbf{B}(\bullet), \mathbf{C}(\mathbf{\Delta}), \mathbf{D}(\boldsymbol{\nabla}), \mathbf{E}(\bullet), \mathbf{F}$ (left-facing solid triangle), $\mathbf{G}$ (rightfacing solid triangle), and $\mathbf{H}(\times)$.

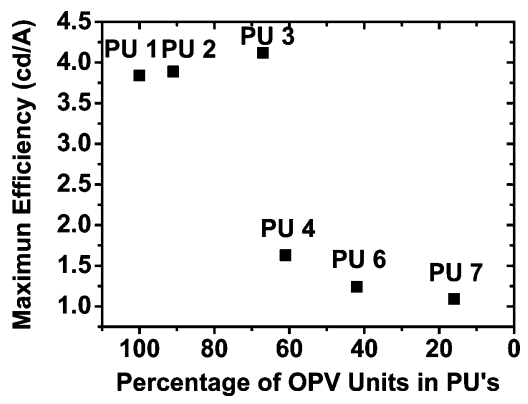

Figure 9. Correlation plot of the maximum device efficiency versus mole percentage of the OPV units in the PUs.

The effects of the PU layer on the turn-on voltage of the OLED are essential. The turn-on voltage, defined as the operational voltage at $100 \mathrm{~cd} / \mathrm{m}^{2}$, significantly dropped from $5.3 \mathrm{~V}$ for the control device $\mathbf{A}$ to $3.5 \mathrm{~V}$ for device $\mathbf{B}, 3.9 \mathrm{~V}$ for device $\mathbf{C}$, and $3.8 \mathrm{~V}$ for device $\mathbf{D}$, respectively. When the weight fraction of the OXD component in the PU increases, the turn-on voltage of the corresponding device increases accordingly.

The presence of the PU layer would also improve the EL efficiency. The EL efficiency for devices $\mathbf{B}-\mathbf{D}$ was improved by 2.4-2.5 times in comparison to that of control device $\mathbf{A}$. When the PU layer of $\mathbf{1}-\mathbf{3}$ was introduced to the OLED, the device shows almost constant efficiency in the high current and brightness regions. The maximum brightness of $14000 \mathrm{~cd} / \mathrm{m}^{2}$ was achieved for device $\mathbf{B}$.

A correlation plot of the maximum EL efficiency versus the composition of the PU layer is shown in Figure 9. An EL efficiency of 3.5-4.0 cd/A was achieved when the OPV: OXD ratio was higher than 1.5. When relative amounts of the OPV component reduced, the maximum EL efficiency of the OLED dropped abruptly to $1 \mathrm{~cd} / \mathrm{A}$. We tentatively attributed this EL efficiency phenomenon to the factor of the balanced carrier transport character in the device. Although the hole mobility of $\alpha$-NPB is known to be higher than the electron mobility of $\mathrm{BeBq}_{2}$, perhaps the relatively inefficient hole injection from the ITO/PEDOT:PSS anode into the $\alpha$-NPB layer may hamper the balanced injection. Unbalanced carrier transport leads to the low efficiency of the device. When the OPV-based PU layer was applied, the PU layer would assist the hole-injection process so that high hole concentration in the HTL that leads to a more chargebalanced condition was achieved. Under these conditions, the EL efficiency was greatly improved. In contrast, when the polymer layer was switched from the OPV-dominant PUs 
Table 3. Fitting Parameters of Operation Lifetimes of Devices A-E in the Accelerated Lifetime Study

\begin{tabular}{lccc}
\hline device & $B_{\mathrm{o}}$ & $C_{1}, k^{\prime}, \tau_{1}(\mathrm{~h})$ & $C_{2}, k^{\prime \prime}, \tau_{2}(\mathrm{~h})$ \\
\hline NPB & 1540 & $0.57,0.67,1.02 \mathrm{~h}$ & $0.31,0.081,8.52 \mathrm{~h}$ \\
OPV & 3562 & $0.60,0.59,1.17 \mathrm{~h}$ & $0.32,0.049,14.1 \mathrm{~h}$ \\
$10: 1$ & 3569 & $0.58,0.58,1.20 \mathrm{~h}$ & $0.35,0.038,18.2 \mathrm{~h}$ \\
$3: 1$ & 2110 & $0.61,0.56,1.23 \mathrm{~h}$ & $0.34,0.041,16.8 \mathrm{~h}$ \\
$1: 1$ & 1613 & $0.49,0.61,1.13 \mathrm{~h}$ & $0.40,0.024,28.8 \mathrm{~h}$
\end{tabular}

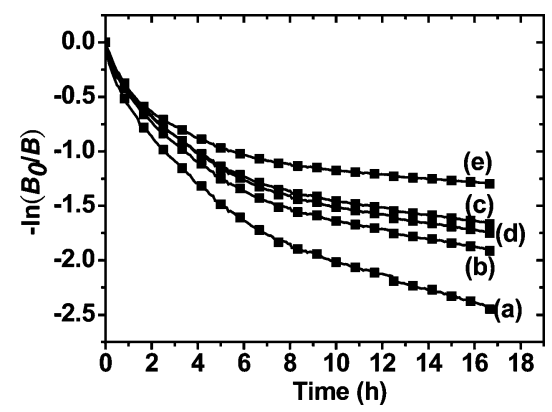

Figure 10. Plot of $-\ln \left(B_{0} / B\right)$ versus time for devices (a) $\mathbf{A}$, (b) $\mathbf{B}$, (c) $\mathbf{C}$, (d) $\mathbf{D}$, and (e) $\mathbf{E}$ in the accelerated lifetime measurements.

to the OXD-dominant PUs, the hole-injection process was substantially retarded. The device was again deviated from the charge-balanced conditions, and therefore the device EL efficiency dropped significantly.

Again, the role of the carbamate spacer is very critical in the EL efficiency. When PU 1 was replaced by the siloxanebased OPV polymer 10, the EL efficiency reduced by almost a factor of 4 to $1.16 \mathrm{~cd} / \mathrm{A}$. In addition, the turn-on voltage increased to $6.3 \mathrm{~V}$.

Accelerated Lifetime Study. Operational lifetime is one of the most demanding properties of OLED devices. Through lifetime studies, the details about the EL process as well as the decay mechanisms could be elucidated. In the present study, we carried out a series of accelerated lifetime measurements with the devices operated at harsh conditions of high current density. (Table 3$){ }^{34}$ In the experiments, the devices were encapsulated by epoxy resin in order to exclude the interferences from moisture and oxygen in the atmosphere. The devices were directly tested after encapsulation without any preannealing treatment. An operating current was set at $100 \mathrm{~mA} / \mathrm{cm}^{2}$. The devices $\mathbf{A}-\mathbf{E}$ exhibited exponential decay of the EL intensity when time progressed. Figure 10 show plots of $-\ln \left(B_{0} / B\right)$ versus time, in which $B_{\mathrm{o}}$ is the starting EL intensity and $B$ is the EL intensity at time $t$. From these plots, one can envisage that the EL intensity decay pattern follows a model of two-phase exponential decay. The devices showed a fast decay at the early stage of operation and a slower decay at the later stage, usually after $4 \mathrm{~h}$.

Nonlinear regression analysis revealed that the decay curves matched well with the equation of $B=B_{0}\left(C_{1} \mathrm{e}^{-k^{\prime} t}+\right.$ $C_{2} \mathrm{e}^{-k^{\prime \prime} t}$ ), where $k^{\prime}$ and $k^{\prime \prime}$ are the decay constants for the fast and slow phases of the decay and $C_{1}$ and $C_{2}$ are the contributions of these two processes to the EL. The halflives were defined as $\tau_{1}=0.69 k^{\prime}$ and $\tau_{2}=0.69 k^{\prime \prime}$. More interesting is the fact that the fast components in all the decays are very similar and almost irrelevant to the applied

(34) Lee, J. H.; Huang, J. J.; Liao, C. C.; Hu, P. J.; Chang, Y. Chem. Phys. Lett. 2005, 402, 335.
PU layer. The values of $\tau_{1}$ fall within the range of $1.1 \pm 0.1$ h. However, the slower components are highly dependent on the applied PU layer. Moreover, the presence of the PU layer would significantly prolong the half-life of the devices by a factor of $2-3$.

Although explanations for these observations are not immediately obvious, the observations of the two-phase exponential decay are common in OLED fabrication. It has been known that annealing pretreatment of an OLED is usually required to obtain devices with stable performance. The fast decay component is attributed to the annealing factor. It is worth reminding that the spectra arise from the emission at the interfacial region of $\alpha-\mathrm{NPB} / \mathrm{BeBq}_{2}$. Recent research revealed that the EL emission at the $\alpha-\mathrm{NPB} / \mathrm{BeBq}_{2}$ interfacial region is very sensitive to both the hole- and electron-transport layer conditions. ${ }^{32} \mathrm{We}$ therefore tentatively assigned the slow decay component in the two-phase exponential decay to the interfacial emission. The present device lifetimes are reasonably long in comparison to other Bebq $_{2}$-based OLEDs reported in the literature. ${ }^{35}$

\section{Conclusion}

In summary, we reported a series of effective novel PUs that improve the performance of the corresponding EL devices, including the turn-on voltage, brightness, efficiency, and lifetime. Compared against the standard device, insertion of a layer of PU 1, 2, or $\mathbf{3}$ enhances the current injection performance so that higher current density and lower driving voltage could be achieved. On one hand, our results show that the OPV units in the matrix are crucial for hole-injection and -transport properties. On the other hand, the polar urethane linkage is also a key component in reducing the driving voltage and improving the device efficiency. Further detailed studies about the emission mechanisms of the devices are ongoing.

\section{Experimental Section}

Instrumentations. ${ }^{1} \mathrm{H}$ NMR spectroscopy was performed on a Bruker 200, 300, or $400 \mathrm{MHz}$ spectrometer. Elemental analyses were performed on an EA Heraeus Vario EL-3 analyzer. FTIR spectra were recorded using a Jasco-480 spectrometer. UV-Vis analyses were performed on a Jasco V-570 UV-Vis spectrophotometer. The number-average and weight-average molecular weights of the polymers were determined by a Waters GPC-480 system with a column of AM GPC Gel $(10 \mu \mathrm{m})$ from American Polymer Standard Company. Dimethylformamide (DMF) as eluent and polystyrene as standard were used in the GPC experiments. TGA and DSC were performed on a TGA Perkin-Elmer TGA-7 and DSC Du Pont 2010 analyzer under a nitrogen atmosphere at a heating rate of $10{ }^{\circ} \mathrm{C} \mathrm{min}^{-1}$. The thickness of the polymer films was measured using an Alpha step Dektak 3030 profilometer. PL spectra of the polymers were recorded using an Hitachi-4500 spectrofluorometer. Electroluminscence was recorded by a Minolta CS-1000 instrument. The $I-V$ and $L-V$ characteristics of the devices were measured by integrating a Keithley 2400 source meter as the voltage and current source and a Minolta CS1000 instrument as the luminance detector. All measurements and device fabrications were performed in air at room temperature under a dust-controlled environment.

(35) Lee, J.-H.; Lin, T.-C.; Liao, C.-C.; Yang, F. H. Proc. SPIE-Int. Soc. Opt. Eng. 2005, 5632, 220-225. 
Device Fabrication. The devices were fabricated with a standard structure of ITO/PEDOT:PSS/PU/ $\alpha-\mathrm{NPB} / \mathrm{Bebq}_{2} / \mathrm{Ca} / \mathrm{Ag}$ described in previous sections. The ITO surface was cleaned by sonication and rinsing in deionized water, Triton-100 water solution, deionized water, acetone, and then methanol. The hole injection of PEDOT: PSS with Triton (15:1) layer was spin-coated (5000 rpm, $60 \mathrm{~s})$ on top of the ITO anode and dried on a hot plate at $130{ }^{\circ} \mathrm{C}$ for $30 \mathrm{~min}$ under vacuum. The PEDOT:PSS layer became a little bit thinner when treated with DMF and about $17 \%$ of thickness lost was observed. Each polymer solution for spin coating, with the concentration of $12 \mathrm{mg} / \mathrm{mL}$ in DMF, was filtered through a membrane filter with the channel size of $0.45 \mu \mathrm{m}$. The PU solution was spin-coated (2000 rpm, $60 \mathrm{~s}$ ) onto the prepared PEDOT:PSS/ ITO anode and dried under reduced pressure for $30 \mathrm{~min}$ at $120^{\circ} \mathrm{C}$. The $\alpha$-NPB and $\mathrm{Bebq}_{2}$ layers and the $\mathrm{Ca}$ and $\mathrm{Ag}$ contacts were deposited on ITO/PEDOT:PSS/PU at pressure below $5 \times 10^{-6}$ Torr. The deposition rate for $\alpha-\mathrm{NPB}$ and $\mathrm{Bebq}_{2}$ is $1-2 \AA / \mathrm{s}$. The deposition rates for $\mathrm{Ca}$ and $\mathrm{Ag}$ cathodes are 1 and $4 \AA$ /s, giving an active area of $0.126 \mathrm{~cm}^{2}$. The thickness for each layer was measured by an Alpha step instrument.

Evaluation of the Polymer Compositions. The compositions of PU 1-PU 7 were estimated according to the UV-Vis absorption spectroscopy. The OPV unit in the polymers has a characteristic absorption that peaked at $360 \mathrm{~nm}$. In the experiments, all the PUs polymer solutions in DMF are prepared at the same concentration of $0.1 \mu \mathrm{g} / \mathrm{mL}$.

The mathematical deductions are derived as follows. We assume that the total weight of the polymers is 1 unit, the weight of OPV, OXD, and IPDI are B, X, and Y, respectively, and the weight of the terminal groups could be ignored. The values of $B, X$, and $Y$ should follow the first relationship of $B+X+Y=$ Total weight $=1$. In addition, since the number (OPV + OXD) and IPDI units are almost in a 1:1 ratio, their values should follow the second relationship of $B / 314.4+X / 254.2=Y / 222.1$, in which the values of 314.1, 254.2, and 222.1 are the molecular weights of OPV, OXD, and IPID, respectively.

The values of $B$ in PUs $\mathbf{2}-\mathbf{6}$ could be evaluated according to their UV absorption intensities at $360 \mathrm{~nm}$. We use the absorption intensity of PU 1 solution, defined as $I_{0}$, as standard. The absorption intensity of PU 2-PU $\mathbf{6}$ solutions is defined as $I^{\prime}$. Since PU $\mathbf{1}$ is a homo PU containing OPV and IPID only, the value of $I_{\mathrm{o}}$ is arising from the OPV with the weight of 0.586. For PU 2-PU 6, their absorption intensity is $I^{\prime}$. Therefore, the weight of OPV in PU 2-PU 6, denoted as $B$, could be calculated according to the equation $B / 0.586=I^{\prime} / I_{0}$. By substitution of the value $B$ into the first and second equations, the composition of the polymers could be solved.

Tetraethyl $\alpha, \alpha^{\prime}$-p-xylenediphosphonate (11). To a two-necked flask were added $N$-bromosuccinimide (180 g, $1.01 \mathrm{~mol}$ ), $p$-xylene (49.2 g, $0.46 \mathrm{~mol})$, and methyl formate $(437 \mathrm{~mL})$. The mixture was stirred and irradiated by a sun lamp $(120 \mathrm{~W})$ for $20 \mathrm{~min}$ at room temperature. AIBN (0.050 g, $0.30 \mathrm{mmol})$ was added and the mixture was heated to $40{ }^{\circ} \mathrm{C}$. After being heated and irradiated for $14 \mathrm{~h}$, the mixture was cooled to room temperature. White precipitates formed were collected by filtration and washed with small portions of methyl formate. The collected precipitates contained the desired $\alpha, \alpha^{\prime}$-dibromo- $p$-xylene and succinimide. The succinimide was removed by washing with water. The white crude product was dried and recrystallized from chloroform to give white needles (58 g, $0.31 \mathrm{~mol}, 66 \%)$ : $\mathrm{mp} 142-143{ }^{\circ} \mathrm{C}\left[\right.$ lit. $\left.143.5^{\circ} \mathrm{C}\right] .{ }^{24}$ ${ }^{1} \mathrm{H}$ NMR $\left(200 \mathrm{MHz}, \mathrm{CDCl}_{3}\right) \delta 7.35$ (s, 4H), 4.45 (s, 4H). ${ }^{13} \mathrm{C} \mathrm{NMR}$ $\left(100 \mathrm{MHz}, \mathrm{CDCl}_{3}\right): \delta$ 138.0, 129.5, 32.8. MS m/z FAB (NBA) HRMS $\left(\mathrm{M}^{+}\right)$calcd for $\mathrm{C}_{8} \mathrm{H}_{8} \mathrm{Br}_{2} 261.8993$, found $\mathrm{C}_{8} \mathrm{H}_{8} \mathrm{Br}_{2} 261.8997$. IR (KBr): 3034, 1229, 2977, 612.
To an oven-dried double-necked flask containing a stir bar were charged $\alpha, \alpha^{\prime}$-dibromo- $p$-xylene $(20.0 \mathrm{~g}, 76.0 \mathrm{mmol})$ and triethyl phosphite (27.6 g, $166 \mathrm{mmol})$. The flask was evacuated and backfilled with argon. The reaction mixture was stirred and heated at reflux temperature for $21 \mathrm{~h}$. The resulting mixture was cooled to room temperature. The excess triethyl phosphite was removed by distillation under reduced pressure. The white solid left inside the flask was collected and recrystallized from ether to give white crystals (18.6 g, $49.0 \mathrm{mmol}, 64 \%): \mathrm{mp} 45-46{ }^{\circ} \mathrm{C}$. [lit. $70{ }^{\circ} \mathrm{C}$ from hexane.${ }^{25}{ }^{1} \mathrm{H}$ NMR $\left(200 \mathrm{MHz}, \mathrm{DMSO}-d_{6}\right): \delta 7.20(\mathrm{~s}, 4 \mathrm{H}), 3.92$ (quintet, $J=7.2 \mathrm{~Hz}, 8 \mathrm{H}), 3.18\left(\mathrm{~d}, J_{\mathrm{HP}}=20.1 \mathrm{~Hz}, 4 \mathrm{H}\right), 1.15(\mathrm{t}, J=$ $7.0 \mathrm{~Hz}, 12 \mathrm{H}) .{ }^{13} \mathrm{C}$ NMR $\left(100 \mathrm{MHz}, \mathrm{DMSO}-d_{6}\right): \delta 135.6,134.8$, 66.5, $37.1(\mathrm{~d}, J \mathrm{cp}=130 \mathrm{~Hz}), 21.4$. MS $m / z$ FAB $(\mathrm{NBA})\left(\mathrm{M}^{+}+\right.$ H) 379.14. HRMS $\left(\mathrm{M}^{+}\right)$calcd for $\mathrm{C}_{16} \mathrm{H}_{28} \mathrm{O}_{6} \mathrm{P}_{2}$ 378.1361, found $\mathrm{C}_{14} \mathrm{H}_{24} \mathrm{O}_{6} \mathrm{P}_{2}$ 378.1366. IR (KBr): 2990, 1517, 1233, $1054 \mathrm{~cm}^{-1}$.

(E,E)-1,4-Bis(2-hydroxystyryl)benzene (8). To a two-necked flask were added with 2-hydroxybenzaldehyde $(22.7 \mathrm{~g}, 0.18 \mathrm{~mol}),(\mathbf{1 1})$ (20.8 g, $54.8 \mathrm{mmol}), \mathrm{LiCl}$ (9.56 g, $0.23 \mathrm{~mol})$, and dried DMF (115 $\mathrm{mL})$. The mixture was stirred for $20 \mathrm{~min}$ at room temperature under nitrogen, cooled in an ice bath, and potassium tert-butoxide $(49.2$ g, $0.44 \mathrm{~mol}$ ) was added slowly. The reaction was continued for 5 $\mathrm{h}$ at room temperature under an inert atmosphere. Aqueous $\mathrm{HCl}$ (1 $\mathrm{N})$ was added slowly in to quench the reaction until the solution was slightly acidic. The yellow precipitate was collected by filtration and washed with water and methanol. Recrystallization from acetone afforded the product as yellow crystals $(13.1 \mathrm{~g}, 41.7 \mathrm{mmol}$, 76.\%). mp 210-211 ${ }^{\circ} \mathrm{C}$ [lit. 230-231 ${ }^{\circ} \mathrm{C}$ from DMF-ether]. ${ }^{26}{ }^{1} \mathrm{H}$ NMR (300 MHz, DMSO-d $\left.d_{6}\right): \delta 9.79(\mathrm{~s}, 2 \mathrm{H}), 7.59-7.54(\mathrm{~m}, 4 \mathrm{H})$, $7.43(\mathrm{~d}, J=16.5,2 \mathrm{H}), 7.21(\mathrm{~d}, J=16.5,2 \mathrm{H}), 7.09(\mathrm{t}, J=6.9$, $2 \mathrm{H}), 6.88-6.81(\mathrm{~m}, 4 \mathrm{H}) .{ }^{13} \mathrm{C}$ NMR (100 MHz, DMSO- $\left.d_{6}\right): \delta 155.0$, 136.7, 128.6, 127.5, 126.6, 126.4, 123.8, 123.3, 119.3, 115.8. MS $m / z$ FAB (NBA) 314.1; HRFAB $\left(\mathrm{M}^{+}\right.$) calcd for $\mathrm{C}_{22} \mathrm{H}_{18} \mathrm{O}_{2} 314.38$, found $\mathrm{C}_{22} \mathrm{H}_{18} \mathrm{O}_{2}$ 314.1310. IR(KBr): 3511, 1491, 813, $763 \mathrm{~cm}^{-1}$.

2,5-Bis(4-hydroxyphenyl)-1,3,4-oxidiazole (9). To a $250 \mathrm{~mL}$ three-neck round-bottomed flask equipped with a magnetic stir bar, nitrogen gas inlet, glass stopper, and distillation head were placed 4-hydroxybenzoic hydrazide (60.9 g, $0.40 \mathrm{~mol}$ ) and phenyl 4-hydroxybenzoate $(85.7 \mathrm{~g}, 0.40 \mathrm{~mol})$. The mixture under nitrogen was heated at $210^{\circ} \mathrm{C}$ for $1 / 2 \mathrm{~h}$. Phenol generated from the reaction was removed by simple distillation. The temperature was gradually raised to and kept at $280{ }^{\circ} \mathrm{C}$ for $1 \mathrm{~h}$. The mixture was allowed to cool. The solidified product mixture, tan in color, was pulverized. Methanol was added $(200 \mathrm{~mL})$ and stirred to wash away the colored impurity. The solid was collected and dried at $50{ }^{\circ} \mathrm{C}$ for $3 \mathrm{~h}$ under vacuum to afford a white solid that was further recrystallized from a mixture of $N, N$-dimethylacetamide (DMAc, $225 \mathrm{~mL}$ ) and water (105 $\mathrm{mL})$ to give essentially pure 9 (46 g, $0.18 \mathrm{~mol}, 45 \%)$ : $\mathrm{mp}$ 331-332 ${ }^{\circ} \mathrm{C}$ [lit. 330-332 ${ }^{\circ} \mathrm{C}$ ]. ${ }^{27}{ }^{1} \mathrm{H}$ NMR (400 MHz, DMSO$\left.d_{6}\right): \delta 10.26(\mathrm{~s}, 2 \mathrm{H}), 7.90(\mathrm{dd}, J=9 \mathrm{~Hz}, 4 \mathrm{H}), 6.94(\mathrm{~d}, J=4.2 \mathrm{~Hz}$, $4 \mathrm{H}) .{ }^{13} \mathrm{C}$ NMR (400 MHz, DMSO- $\left.d_{6}\right): \delta 163.70,160.9,128.7$, 116.4, 114.5. MS $m / z$ FAB (NBA) HRMS $\left(\mathrm{M}^{+}\right.$) calcd for $\mathrm{C}_{8} \mathrm{H}_{8} \mathrm{Br}_{2}$ 255.0770, found $\mathrm{C}_{8} \mathrm{H}_{8} \mathrm{Br}_{2}$ 255.0773.

Synthesis of PUs 1-7: A Typical Procedure. OPV 8 (0.942 $\mathrm{g}, 3 \mathrm{mmol})$, isophorone diisocyanate $(0.7 \mathrm{~g}, 3.15 \mathrm{mmol})$, and dried DMF $(15 \mathrm{~mL})$ were charged in a two-necked flask and stirred for $24 \mathrm{~h}$ at room temperature under nitrogen. 4-tert-Butylphenol $(0.045$ $\mathrm{g}, 0.3 \mathrm{mmol}$ ) was added and stirred for $24 \mathrm{~h}$ to terminate the reaction. After the reaction was complete, the polymer was precipitated by dropwise addition of the reaction mixture into methanol. The precipitation procedure in $\mathrm{MeOH}$ was repeated. The PU was collected and washed with toluene and chloroform to remove any DMF. The final PU was collected and dried under vacuum conditions for about $12 \mathrm{~h}$ at $100-105^{\circ} \mathrm{C}$. $(1.6 \mathrm{~g}, 92 \%)$ : Anal. Calcd based on the calibrated composition listed in Table 1: 
C, 76.2; H,6.8; N, 5.10\%. Found: C, 76.5; H,6.8; N: 5.3\%; For the synthesis of the copolymers $\mathbf{2 - 7}$, the feeding ratios of the reagents and the calibrated compositions were summarized in Scheme 3 and Table 1 . The characterization data are summarized as follows: PU 2 (83\%): Anal. Calcd based on the calibrated composition listed in Table 1: C, 75.4; H, 6.7; N, 5.6\%. Found: C, 73.7; H, 6.6; N, 5.8\%. PU 3 (91\%): Anal. Calcd based on the calibrated composition listed in Table 1: C, 73.1; H, 6.6; N, 7.0\% Found: C, 72.3; H, 7.1; N, 6.5\%. PU 4 (94\%) Anal. Calcd based on the calibrated composition listed in Table 1: C, 72.5; H, 6.5; N, 7.4\%. Found: C, 72.4.; H, 7.8; N, 7.3\%. PU 5 (82\%): Anal. Calcd based on the calibrated composition listed in Table 1: C, 70.6; H, 6.4; N, 8.6\%. Found: C, 72.1; H, 7.2; N, 7.5\%. PU 6
(86\%): Anal. Calcd based on the calibrated composition listed in Table 1: C, 67.8; H, 6.2; N, 10.3\%. Found: C, 69.4; H, 7.9; N, 8.0\%. PU 7 (92\%): Anal. Calcd based on the calibrated composition listed in Table 1: C, 66.0; H, 6.0; N, 11.5\%. Found: C, 63.8; H, $6.49 ; \mathrm{N}, 10.87$.

Acknowledgment. This work was supported by Ministry of Economic Affairs (93-EC-17-A-08-S1-0015) and National Science Council (NSC 94-2113-M-002-026) of Taiwan, and Advanced Polymer Nano Technology Research Center.

CM060124W 